\title{
Sensitivity-based Multidisciplinary Optimal Design of a Hydrostatic Rotary Table with Particle Swarm Optimization
}

\author{
Qiang Cheng ${ }^{1,2}$ - Chengpeng Zhan ${ }^{1}$ - Zhifeng Liu ${ }^{1, *}$ - Yongsheng Zhao ${ }^{1}$ - Peihua Gu ${ }^{3}$ \\ ${ }^{1}$ Beijing University of Technology, China \\ ${ }^{2}$ Huazhong University of Science and Technology, \\ Digital Manufacturing Equipment and Technology Key National Laboratories, China \\ 3 Department of Mechatronics Engineering, Shantou University, China
}

In five-axis machine tools, a rotary table is often used as a means for providing rotational motion and supporting the workpiece. Its rigidity, precision and carrying capacity is directly related to the machining ability and the accuracy of the NC machine tool. Traditional rotary table design is normally performed by teams, each with expertise in a specific discipline, which causes excessive iterations and cannot provide users with products of reliable working performance and bearing capacity. To achieve an optimal design with less cost and better performance, this paper considers the mutual interaction of hydrostatics and structure disciplines involved in the design of hydrostatic rotary tables, and a sensitivity-based multidisciplinary optimal design procedure of a hydrostatic rotary table is proposed. Sensitivity analysis is adopted to identify the key design parameters that have a major influence on the performance of rotary tables to improve the convergence of optimization process. The constrained multi-objective optimization problem is solved by using a particle swarm optimization approach. A hydrostatic rotary table of a five-axis heavy duty machine tool is selected as an illustration example. The results show that the proposed method can realize the multidisciplinary optimization resulting in a rotary table of good rigidity and bearing capacity.

Keywords: hydrostatic rotary table, sensitivity analysis, NC machine tool, particle swarm optimization, multidisciplinary optimal design

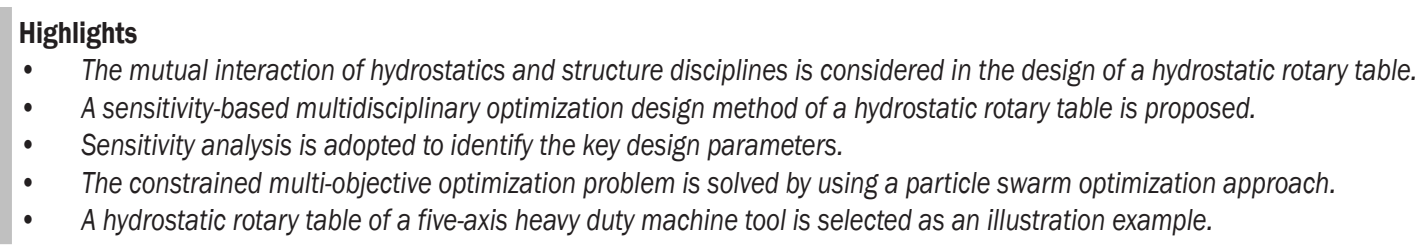

\section{INTRODUCTION}

Numerical control (NC) machine tools are one of the most important components in modern manufacturing facilities, and high-performance machines are required. The accuracy of the machine tool motion has a significant influence on the quality of the machining operations and the machined parts. The industrial demand for manufacturing geometrically complex parts often calls for multi-axis machine tools to have a tool orientation capability [1]. Five-axis machine tools are becoming increasingly popular and can be found in a large number of manufacturing applications [2]. However, such tools are usually more complicated and less rigid in structure in comparison with traditional three-axis machine tools, which leads to lower machining accuracy [1]. In five-axis machine tools, a rotary table (or rotary-tilting table) is often used as a means for providing rotational motion and is now widely used in the machine shop. As a consequence, a resultant volumetric error, i.e. the relative error between the cutting tool and the machined part, is more complicated than three-axis machine tools. Hence, the reduction of the error to improve the accuracy of the machine tool is crucial.

In a five-axis machine tool, each element contributes some degree of inaccuracy due to their manufacturing and assembling limitations, whereas machine structure stiffness, machine foundation, machine control, operating systems, and environmental conditions further add some inaccuracy. The errors/ inaccuracies can be reduced with the structural improvement of the machine tool through better design, manufacturing and assembly practices [3]. In heavy duty 5-axis machine tools, a hydrostatic rotary table handles supporting and rotating the workpiece, and the location of a rotary axis constitutes a significant error source [4]. Therefore, the accuracy of the rotary table is crucial for part manufacturing with multi-axis machine tools [1]. Its rigidity, precision and carrying capacity is directly related to the machining ability and the accuracy of the NC machine tool.

Due to the lack of effective means of analysis and experiment, the designed rotary table cannot 
provide users with reliable working performance and bearing capacity, which directly affects the machining accuracy, and the bearing grounding will cause serious economic loss to users. Therefore, how a hydrostatic rotary table is designed for a heavy duty five-axis machine tool is very important for machine manufacturers, which requires determining the relations between the design variables that refer to different disciplines and their effects on various performance objectives. Traditional engineering design is normally performed by teams, each with expertise in a specific discipline, such as hydrostatics or structures. Each team uses the experience and judgment of its members to develop a workable design, usually sequentially. This causes contradictory results from different design teams; therefore, multiple revisions throughout the design process may result [5]. These excessive iterations will clearly increase the cost and time of the design process.

Starting in the $20^{\text {th }}$ century, engineers decided to use multidisciplinary design optimization (MDO) approaches to solve similar problems [5]. MDO is widely studied and applied in both academia and industry, and can reduce the time required to execute the design process. By using MDO methods, designers may quickly and efficiently conduct alternative design points over a wide range of parameters. MDO has become essential for solving complex engineering design problems. MDO processes allow an evaluation of the constraints for multiple disciplines from the early stages of the design; the expense of making approximations or corrections is thus reduced.

Although the multidisciplinary optimization has been successfully applied in the aircraft industry and resulted in more reliable and better products, it is rarely used in the design of machine tools. To make a high-performance machine, not only can the kinematic functions of mechanisms used in the machine be optimized but also the structure and even the controllability of the mechanisms must be optimized. Therefore, the MDO technique can be used to improve the overall performance of machines. Based on these reasons, the aim of this paper is to present a multidisciplinary optimization method for a hydrostatic rotary table based on sensitivity analysis. The main contribution of this paper is two-fold. Firstly, the proposed multidisciplinary optimization method takes into comprehensive consideration the hydrostatics and structure disciplinary characteristics, which can reduce the iterative modification caused by sequential design by experts in different disciplines. Secondly, because a hydrostatic rotary table is a complex product and has many design parameters, sensitivity analysis is introduced to identify the key design parameters that have significant influence on the performance; therefore, the optimization is realized with quick convergence.

The remainder of this paper is organized as follows. In next section, the background reviews of sensitivity-based MDO are given. The third section presents multidisciplinary characteristics of modelling in both the hydrostatics and structure disciplines. Subsequently, MDO based on sensitivity analysis is implemented in Section 4. Section 5 demonstrates the proposed method with a designed hydrostatic rotary table. The final section contains the conclusions.

\section{BACKGROUNDS}

\subsection{Multidisciplinary Design Optimization}

MDO is essential to the design and operation of a complex system, because it simultaneously takes into consideration all relevant disciplines to find the global optimum that is superior to a solution from a sequence of local optimizations in individual disciplines. MDO can be traced back to Schmit [6] and Haftka [7], who extended their experience in structural optimization to include other disciplines. The intention was to address these challenges and, in particular, the coupling within design hierarchies and between disciplines [8]. The research area of MDO has been intensively investigated over the previous decades [8], and the focus of MDO has shifted dramatically, as faculties and researchers are finding new ways to use MDO methods and tools on a wide array of problems [9] and [10]. There have been many advances to capture, represent, and propagate couplings in analysis, design, and organizations, yet the design of complex engineered systems continues to be challenging.

MDO can enhance system design by exploiting synergies among different disciplines. However, there are two major challenges in applying MDO: organizational and computational complexities. The organizational complexities mean that a simultaneous consideration of multiple disciplines may increase the difficulty of data origination and coordination between different disciplines or different computeraided engineering (CAE) software. The increased complexity of the optimization system inevitably causes increased amounts of computing, and the convergence problem increases the computational complexities [11]. To address these two challenges, one of the research focuses in MDO has been on optimization procedure [9] and [10]. Optimization procedures can be categorized into two types: 
single-level and multi-level approaches. Single level approaches employ a system optimizer for the whole problem, which is straightforward to understand and easy to implement. Multi-level approaches utilize decomposition strategies to allow disciplinary autonomy in design and optimization while managing interdisciplinary consistency via system coordination [12].

One of the first applications of MDO was aircraft wing design, where aerodynamics, structures, and controls are three strongly coupled disciplines [13]. Since then, the application of MDO has been extended to complete aircraft [14] and a wide range of other engineering systems, such as bridges [15], buildings [16], automobiles [17] and [18], ships [19], and spacecraft [20]. Yifei et al. [21] proposed the framework of multidisciplinary energy-saving optimization design for bridge cranes, and realized metal structures level, transmission design level, and electrical system design as well as the optimization design of bridge cranes.

There have been many summaries of MDO since the 1990s. In a collection of articles Kroom [22] provided a comprehensive overview of MDO, including a description of both monolithic and distributed architectures. Sobieszczanski-Sobieski and Haftka [23] presented a detailed summary of the MDO literature. Because one of the most important considerations when implementing MDO is how to organize the discipline analysis models, approximation models, and optimization software in concert with the problem formulation, a combination of problem formulation and organizational strategy is referred to as an MDO architecture. Martins and Lambe [24] provided a survey of all the architectures that had been presented at length in the literature.

In engineering design, to achieve high reliability and safety in complex and coupled multidisciplinary systems, reliability-based multidisciplinary design optimization (RBMDO) has received increasing attention. Since the 1990s, the consideration of the effect of uncertainty has been one of the focus areas in engineering design [25] and [26]. RBMDO can improve the system design by exploiting the synergistic effects between coupled disciplines by interdisciplinary collaboration, and can also enhance the reliability by taking uncertainties into consideration in the design phase [27]. There are successful applications of RBMDO clearly demonstrating its efficacy [28]. Yao et al. [27] summarized two categories of RBMDO procedures: the single level procedure, and the decomposition and coordination-based procedure, which were mostly developed under random uncertainties with probability theory [8].

\subsection{Hydrodynamics Design and Analysis}

The design of hydrostatic rotary tables has been studied by researchers in recent years, mostly concentrating on the hydrostatic part. Traditional optimization research work is mostly based on single objective, such as pump power, friction factor, bearing-capacity [29] to [31], and many researchers have used this method to design the hydrostatic bearings [32] to [35]. Lin studied the influence of factors including surface roughness and inertia, and optimized the bearing [34]. Zhao et al. used Isight software to optimize hydrostatic guideways with multiple pockets for a heavy duty CNC vertical turning mill [36]. Solmaz compared single and multi-objective optimization solutions of hydrostatic radial bearings and thrust bearings [37].

Several researchers have intensively studied the optimization of hydrostatic bearings. As for the rotary table, because it has a huge volume and many rib plates, and because there are many design parameters, it is difficult to realize the multidisciplinary optimization quickly and with good convergence. Fortunately, sensitivity analysis can evaluate the variation in dynamic model outputs with respect to variation in model parameters. Therefore, sensitivity analysis needs to be taken into account in order to weigh all of the parameters to get a more accurate optimization results.

\subsection{Sensitivity Analysis}

Sensitivity analysis (SA) can be used to identify the effect of system parameter uncertainty variation on system responses and to identify the most critical parameters [38] and [39]. It is one approach to identifying and quantifying the relationships between input and output uncertainties [40], and can evaluate the variation in dynamic model outputs with respect to variation in model parameters. Therefore, SA can be used to perform uncertainty analysis, estimate model parameters, analyse experimental data, guide future data collection efforts, and suggest the accuracy to which the parameters must be estimated [41]. For a review on methods for SA, see Saltelli et al. [42], and Helton and Davis [43].

SA is divided into the local sensitivity analysis (LSA) and global sensitivity analysis (GSA) [44]. LSA, emphasizing the effect of small parameter variations on model responses, is used to determine 
model response changes with an individual parameter. GSA is applied to understand how the model response varies with the model parameters to determine interaction strengths among the parameters, such as Fourier amplitude sensitivity test, regressionbased methods, Sobol method, and McKay's oneway ANOVA method [45]. The global SA examines the global response (averaged over the variation of all the parameters) of model output(s) by exploring a finite (or even an infinite) region. The local SA, easier to implement, can only inspect one point at a time, and the sensitivity index of a specific parameter is dependent on the central values of the other parameters.

There are several numerical methods for the calculation of LSA, e.g. finite differences [44], iterative approximation with directional derivatives [46] or the direct decoupled method [47], but the calculated values should be identical within the numerical accuracy of the method used. Common GSA techniques include correlation and regression modelling, variance decomposition analysis [48], factorial screening [49], and partitioning based generalized sensitivity analysis. Saltelli et al. provided an extensive list of other techniques that have also been found useful in this context [44].

\section{MULTIDISCIPLINARY CHARACTERISTICS MODELING}

\subsection{Structure of Hydrostatic Rotary Table}

According to engineering experience, a heavy hydrostatic rotary table whose diameter is more than 5 metres will have double support circles, as shown in Fig. 1. Generally, a hydrostatic rotary table consists of five parts: the oil supply system, the drive system, the countertop, the base system, and the support system. The countertop and support system are the most important parts of the rotary table, which are needed to focus on during the design process. The support system includes supporting oil pads, preloaded oil pads and the radial bearing. The supporting oil pad is a circular step pad, and a rotary table has 24 supporting pads in total. They are arranged in two supporting circles and the number of pads in the second supporting circle is twice of that of the first supporting circle. The preloaded oil pad is annular step recess pad and provides a pre-pressure that can enhance the stiffness of the turntable. The radial bearing has four recesses and is mounted in the centre of the turntable. The supporting system has twenty-nine pads (include 24 supporting pads, 1 preload pad and 4 radial pads) which need a constant flow of oil, but it is expensive

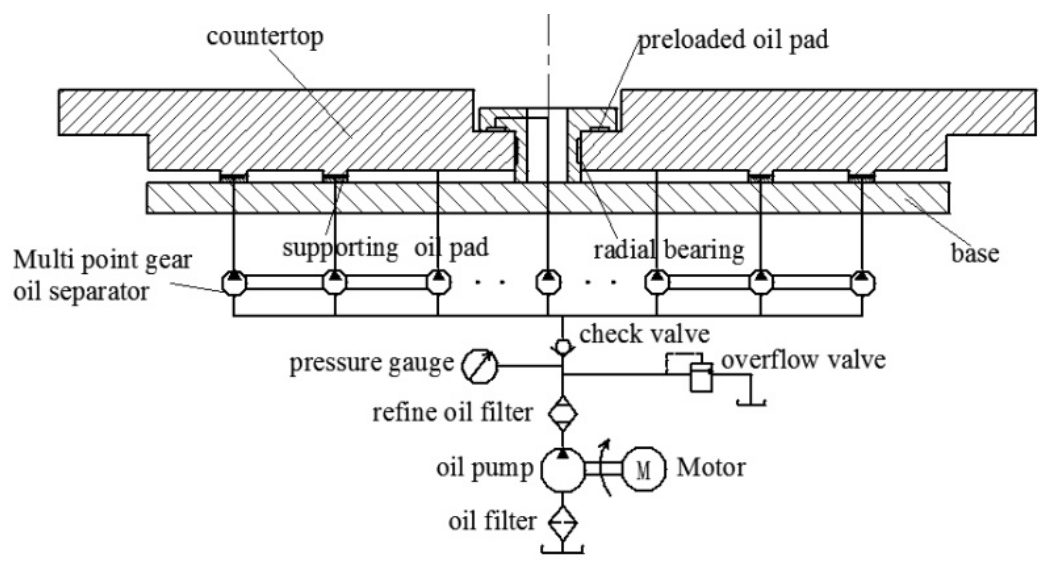

Fig. 1. The structure of hydrostatic rotary table

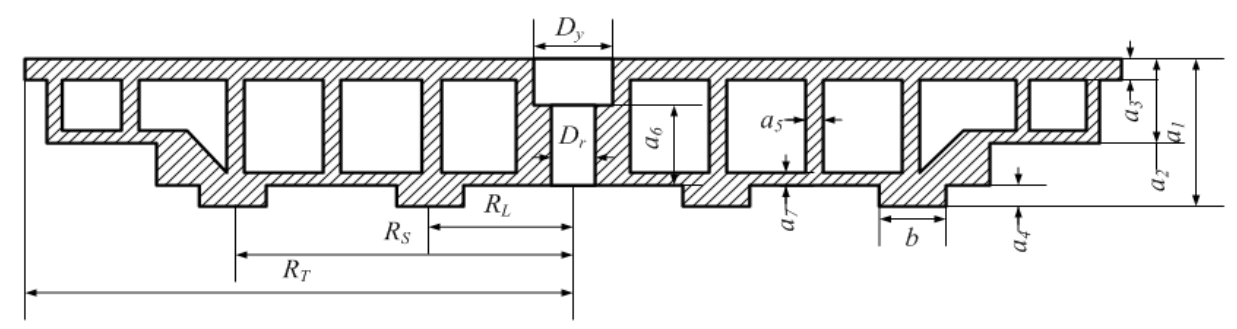

Fig. 2. The structure of countertop 
and unnecessary to assemble twenty-nine constant displacements. The hydrostatic oil supply is divided into many portions by multi-point gear oil separators, which are always connected by a shaft. Therefore, only a small number of oil pumps can supply all the oil pads.

For multi-pad hydrostatic bearings, compensation is needed, because of the issues of mutual influence between the oil pads. Restrictors (e.g. orifice, capillary, cylindrical-spool valves and so on) are widely used as compensation devices as described in detail in references [29] to [31]. Constant flow is another effective compensation method via the use of multi-point gear oil separators and so every pad has the same flow rate, and there is little interaction between the oil pads. All the equal gear pumps are connected by one shaft, which forces them to rotate at the same speed and produce the same flow rate. A detailed compensation theory of constant flow is described on page 17 of reference [30].

\subsection{Characteristic Modelling of Structural Discipline}

The rotary table countertop structure diagram is shown in Fig. 2, and it is mainly composed of a rib structure. The size parameters directly determine the performance of the countertop. Ideally, the rotary table should have a minimum mass and deformation while having the best static and dynamic performance. The decrease of mass, structure deformation and the increase of natural frequency can not only reduce costs but also enhance the accuracy of the rotary table. Therefore, the optimization goals for the structure discipline are to minimize the mass and deformation and to maximize the natural frequency. The value of countertop's mass, deformation and natural frequency are determined by all the design parameters. Then, the mass function, deformation function, and modal frequency function can be written as follows:

$$
\begin{aligned}
& \text { freq }=f_{r}\left(a_{1}, a_{2}, a_{3}, a_{4}, a_{5}, a_{6}, a_{7}, R_{L}, R_{S}, D_{y}, D_{r}, b\right), \\
& \text { mass }=f_{m}\left(a_{1}, a_{2}, a_{3}, a_{4}, a_{5}, a_{6}, a_{7}, R_{L}, R_{\mathrm{S}}, D_{y}, D_{r}, b\right), \\
& \text { deform }=f_{d}\left(a_{1}, a_{2}, a_{3}, a_{4}, a_{5}, a_{6}, a_{7}, R_{L}, R_{S}, D_{y}, D_{r}, b\right) .
\end{aligned}
$$

$R_{T}$ is a design parameter of the countertop and has some influence on its mass, deformation, and natural frequency. In Eqs. (1) to (3), $R_{T}$ is not considered not because of its lowest influence but that it is mainly decided by the machining capacity of the $\mathrm{NC}$ machine tool. In other words, $R_{T}$ is decided by the designer of machine tool not by the designer of the rotary table.
Therefore, when the design of the rotary table is started to $R_{T}$ has already been determined as a constant value. The objective function in structure part can be written as:

$$
\boldsymbol{f}_{1}=\max [\text { freq, }- \text { mass },- \text { deform }],
$$

where the minus sign in Eq. (4) means the optimization goals is minimum.

\subsection{Characteristic Modelling of Hydrodynamics Discipline}

\subsubsection{Establishment of Reynolds Equations}

In this study, it is assumed that thin film lubrication theory is applicable, and the flow in bearing is isothermal, laminar and axisymmetric. The Reynoldstype equation and the radial fluid flow equations can be given as (The specific derivations are shown in Appendix):

$$
\begin{gathered}
\frac{1}{r} \frac{\partial}{\partial r}\left(\frac{r h^{3}}{12 \eta} \frac{\partial p}{\partial r}\right)=\frac{\partial h}{\partial t} \\
Q(r)=-\frac{\pi r h^{3}}{6 \eta} \frac{\partial p}{\partial r}
\end{gathered}
$$

where $r$ is the radius, $h$ is the film thickness, $p$ is the film pressure, $t$ is the time, and $\eta$ is the lubricant viscosity.

\subsubsection{Calculation of Supporting Oil Pad}

As shown in Fig. 3, the supporting pad of the rotary table is a circular recess pad, $R_{1}$ and $R_{2}$ are the inner radius and outer radius of the pad respectively, $Q_{0}$ is the flow rate supply to the pad.

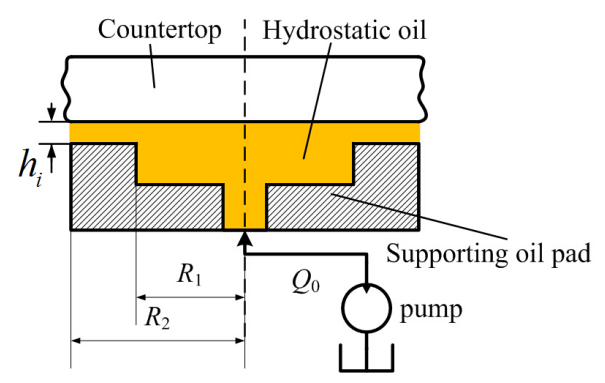

Fig. 3. The structure of the supporting oil pad

By solving Eq. (5) with boundary conditions: $p_{i}\left(r=R_{1}\right)=p_{0 i} ; p_{i}\left(r=R_{2}\right)=0$, the film pressure profile $p_{i}(r)$ can be obtained. Then, by substituting $p_{i}(r)$ into Eq. (6), recess pressure $p_{0 i}$ can be obtained. Finally, 
the load-carrying capacity of the bearing is calculated by integrating the film pressure.

$$
F_{i}=\frac{3 \eta\left[2 Q_{0}-\pi\left(R_{2}^{2}+R_{1}^{2}\right) \frac{\partial h_{i}}{\partial t}\right]\left(R_{2}^{2}-R_{1}^{2}\right)}{2 h_{i}^{3}},
$$

where the detailed derivations of $p_{0 i}, p_{i}(r)$ and $F_{i}$ are shown in Appendix.

In addition, the stiffness, the damping coefficients and the pump power are obtained as follows:

$$
\left\{\begin{array}{l}
K_{S i}=\frac{9 Q_{0} \eta\left(R_{2}^{2}-R_{1}^{2}\right)}{h_{i}^{4}} \\
C_{S i}=\frac{3 \pi \eta\left(R_{2}^{4}-R_{1}^{4}\right)}{2 h_{i}^{3}} \\
N_{T i}=\frac{6 \eta \ln \left(\frac{R_{2}}{R_{1}}\right) Q_{0}^{2}}{\pi h_{i}^{3}}
\end{array},\right.
$$

\subsubsection{The Calculation of the Preloaded Oil Pad}

The preloaded oil pad is an annular recess pad as shown in Fig. $4, R_{C 1}, R_{C 2}, R_{C 3}, R_{C 4}$ are the structural parameters of the annular recess pad.

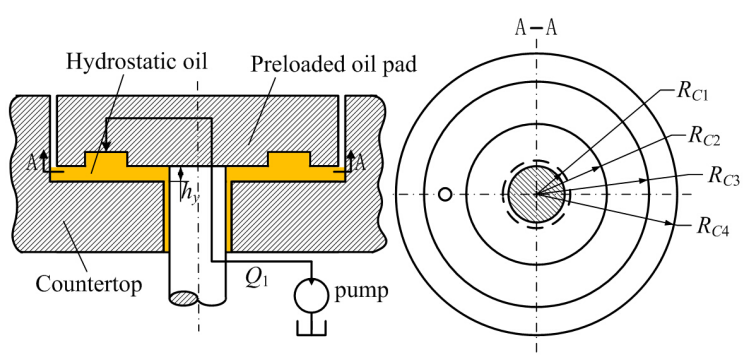

Fig. 4. The structure of preloaded oil pad

The load-carrying capacity of the bearing can be calculated by integrating the hydrostatic film pressure:

$$
\begin{aligned}
& F_{y}=\frac{3 \eta}{2 h_{y}^{3} \ln \left(\frac{R_{C 1}{ }^{R} C 3}{R_{C 2}{ }^{R} C 4}\right)} \times \\
& \times\left[2 Q _ { 1 } \left(\left(R_{C 4}^{2}-R_{C 3}^{2}\right) \ln \left(\frac{R_{C 1}}{R_{C 2}}\right)+\left(R_{C 1}^{2}-R_{C 2}^{2}\right) \ln \left(\frac{R_{C 3}}{R_{C 4}}\right)+\right.\right. \\
& +\pi\left(\begin{array}{l}
\left.\left(R_{C 1}^{4}-R_{C 2}^{4}+R_{C 3}^{4}-R_{C 4}^{4}\right) \ln \left(\frac{{ }_{C 1}{ }^{R} C 3}{R_{C 2}{ }^{R} C 4}\right)-\right) \\
-\left(R_{C 1}^{2}-R_{C 2}^{2}+R_{C 3}^{2}-R_{C 4}^{2}\right)^{2}
\end{array}\right),
\end{aligned}
$$

where $p_{0 y}$ and $p_{y}(r)$ are the recess pressure and the film pressure profile of a preloaded oil pad, respectively.

Then the stiffness, the damping coefficients and the pump power are obtained as follows:

$$
\begin{gathered}
K_{y}=\frac{9 Q_{1} \eta\left(\left(R_{C 4}^{2}-R_{C 3}^{2}\right) \ln \left(\frac{R_{C 1}}{R_{C 2}}\right)+\left(R_{C 1}^{2}-R_{C 2}^{2}\right) \ln \left(\frac{R_{C 3}}{R_{C 4}}\right)\right)}{h_{y}^{4} \ln \left(\frac{R_{C 1} R_{C 3}}{R_{C 2} R_{C 4}}\right)}, \\
C_{y}=\frac{3 \eta \pi\left(\begin{array}{c}
\left(R_{C 1}^{4}-R_{C 2}^{4}+R_{C 3}^{4}-R_{C 4}^{4}\right) \ln \left(\frac{R_{C 1} R_{C 3}}{R_{C 2} R_{C 4}}\right)- \\
-\left(R_{C 1}^{2}-R_{C 2}^{2}+R_{C 3}^{2}-R_{C 4}^{2}\right)^{2}
\end{array}\right)}{2 h_{y}^{3} \ln \left(\frac{R_{C 1} R_{C 3}}{R_{C 2} R_{C 4}}\right)}, \\
N_{T y}=\frac{6 \eta \ln \left(\frac{R_{C 4}}{R_{C 3}}\right) \ln \left(\frac{R_{C 2}}{R_{C 1}}\right) Q_{1}^{2}}{\pi h_{y}^{3} \ln \left(\frac{R_{C 4} R_{C 2}}{R_{C 3} R_{C 1}}\right)},
\end{gathered}
$$

where the detailed derivations of $p_{0 y}, p_{y}(r)$ and $F_{y}$ are shown in Appendix.

\subsubsection{Optimization Objective Function in Hydrostatics}

The support system consists of supporting oil pads, preloaded oil pad and radial bearing. So the stiffness, damping coefficients and the pump power can be calculated as follows:

$$
\left\{\begin{array}{l}
K_{Z}=\sum_{i=1}^{n 1} K_{s i}+\sum_{j=1}^{n 2} K_{s j}+K_{y} \\
K_{\mathrm{t}}=\sum_{i=1}^{n 1} K_{s i}\left(R_{L} \sin \left(\varphi_{i}\right)\right)^{2}+\sum_{j=1}^{n 2} K_{s j}\left(R_{S} \sin \left(\varphi_{j}\right)\right)^{2} \\
C_{Z}=\sum_{i=1}^{n 1} C_{s i}+\sum_{j=1}^{n 2} C_{s j}-C_{y} \\
C_{t}=\sum_{i=1}^{n 1} C_{s i}\left(R_{L} \sin \left(\varphi_{i}\right)\right)^{2}+\sum_{j=1}^{n 2} C_{s j}\left(R_{S} \sin \left(\varphi_{j}\right)\right)^{2} \\
N_{T}=\sum_{i=1}^{n 1} N_{T i}+\sum_{j=1}^{n 2} N_{T j}+N_{T y}
\end{array}\right.
$$

Forces on the turntable are balanced in the initial state, so we have Eq. (14).

$$
\sum_{i=1}^{n 1} F_{i}+\sum_{j=1}^{n 2} F_{j}-F_{y}-G=0
$$

Turntable manufacturers tend to determine the film thickness of the supporting oil pads and the preloaded oil pad at first and then determine the flow 
rate of the oil pad, so in this work the flow rate of preload oil pad $Q_{1}$ is calculated by Eq. (14).

The objective function can be written as:

$$
\boldsymbol{f}_{2}=\max \left[K_{Z}, K_{t}, C_{Z}, C_{t},-N_{T}\right]
$$

Therefore, the total objective function in hydrostatics discipline can be written as:

$$
f=\min \left[f_{1}, f_{2}\right] .
$$

\section{MDO BASED ON SENSITIVITY ANALYSIS}

\subsection{Sensitivity Analysis}

Different design parameters of the rotary table have different influences on its performance. Because there are many design parameters, it is difficult to realize optimization with a good convergence. Therefore, it is feasible to select the key parameters that have a significant influence on performance to implement optimization. The sensitivity is the gradient of a concern target to the design parameters of the rotary table, and SA can help identify the key parameters [43].

Here, SA can be divided into two parts: the first part is about the rotary table structure SA; the second part is about hydrostatic part SA. The derivations of objective function $\boldsymbol{f}_{1}, \boldsymbol{f}_{2}$ to the parameters $\boldsymbol{x}_{1}$ and $\boldsymbol{x}_{2}$ can be found respectively.

Where,

$$
\begin{gathered}
\boldsymbol{x}_{1}=\left[a_{1}, a_{2}, a_{3}, a_{4}, a_{5}, a_{6}, a_{7}, R_{L}, R_{\mathrm{S}}, D_{y}, D_{r}, b\right], \\
\boldsymbol{x}_{2}=\left[R_{\mathrm{S}}, R_{\mathrm{L}}, R_{1}, R_{2}, R_{C 1}, R_{C 2}, R_{C 3}, R_{C 4}, \eta, Q_{0}, n 1, h_{s 0}, h_{y 0}\right] .
\end{gathered}
$$

So, the sensitive matrix can be written as:

$$
\mathbf{S I}\left[\boldsymbol{f}_{1}, \boldsymbol{f}_{2}\right]=\left[\begin{array}{cccccc}
\frac{\partial \text { freq }\left(\boldsymbol{x}_{1}\right)}{\partial a_{1}} & \ldots & \frac{\partial \operatorname{deform}\left(\boldsymbol{x}_{1}\right)}{\partial a_{1}} & \frac{\partial K_{Z}}{\partial R_{S}} & \ldots & \frac{\partial N_{T}}{\partial R_{S}} \\
\ldots & \ldots & \ldots & \ldots & \ldots & \ldots \\
\frac{\partial \text { freq }\left(\boldsymbol{x}_{1}\right)}{\partial b} & \ldots & \frac{\partial \operatorname{deform}\left(\boldsymbol{x}_{1}\right)}{\partial b} & \frac{\partial K_{Z}}{\partial h_{y 0}} & \ldots & \frac{\partial N_{T}}{\partial h_{y 0}}
\end{array}\right]
$$

As for the first part, a parameterized FEM model is established to calculate $\mathbf{S I}\left(\boldsymbol{f}_{1}\right)$ in ANSYS software, and the sensitivity of the second part is calculated in MATLAB according to Eq. (13) and Eq. (17). The partial differential equations in Eq. (17) can be solved by numerical method. For example, $\partial$ freq $\left(\boldsymbol{x}_{1}\right) / \partial a_{1}$ can be calculated by converting it into a differential equation $\left[\right.$ freq $\left.\left(a_{1 h}\right)-f r e q\left(a_{1 l}\right)\right] /\left(a_{1 h}-a_{1 l}\right)$, in which $a_{1 h}$ and $a_{1 l}$ are upper boundaries and lower boundaries of parameter $a_{1}$ respectively, and all design parameters have no change except $a_{1}$ in the calculation of freq $\left(a_{1 h}\right)$ and freq $\left(a_{1 l}\right)$. In this way, Eq. (17) becomes Eq. (18):

$$
\mathbf{S I}\left[\boldsymbol{f}_{1}, \boldsymbol{f}_{2}\right]=\left[\begin{array}{cccccc}
\frac{\operatorname{freq}\left(a_{1 h}\right) \text {-freq }\left(a_{1 l}\right)}{\Delta a_{1}} & \ldots & \frac{\partial \operatorname{deform}\left(a_{1 h}\right) \text {-ddeform }\left(a_{1 l}\right)}{\Delta a_{1}} & \frac{K_{Z}\left(R_{S h}\right)-K_{Z}\left(R_{S l}\right)}{\Delta R_{S}} & \ldots & \frac{N_{T}\left(R_{S h}\right)-N_{Z}\left(R_{S l}\right)}{\Delta R_{S}} \\
\ldots & \ldots & \ldots & \ldots & \ldots & \ldots \\
\frac{\operatorname{freq}\left(b_{h}\right)-\text { freq }\left(b_{l}\right)}{\Delta b} & \ldots & \frac{\partial \operatorname{deform}\left(b_{h}\right) \text {-ddeform }\left(b_{l}\right)}{\Delta b} & \frac{K_{Z}\left(w_{h}\right)-K_{Z}\left(w_{l}\right)}{\Delta w} & \ldots & \frac{N_{T}\left(w_{h}\right)-N_{Z}\left(w_{l}\right)}{\Delta w}
\end{array}\right] .
$$

\subsection{MDO Strategy}

The MDO strategy starts from the design problem itself and is aimed at calculation structure and information organization. It is necessary to decompose the coupling relationship for multidisciplinary analysis and optimization. Information organization of MDO can make virtual design between different disciplines and different CAE analysis software possible and practical. With current computing resources, techniques of multidisciplinary optimization can be integrated effectively with multi-objective optimization algorithms to search for optimal designs; the detailed process is illustrated in Fig. 5. Isight is a generic software framework for the integration, automation, and optimization of design processes
[50]. In this optimization, commercial software, such as CATIA, ANSYS, and MATLAB, are integrated with Isight so that they can input design parameters and output analysis results through a unified software platform

The optimization implementation is completed in five steps. Step 1: start Isight software; Step 2: set up in Isight software including connect MATLAB, CATIA, ANSYS with Isight, drag optimization component to the task, and set up boundary conditions, variables, objectives and other optimization parameters; Step 3: Run Isight and optimization component; Step 4: Iterations are implemented until the maximum iteration steps are attained; Step 5: Output the results and the optimization is completed. 


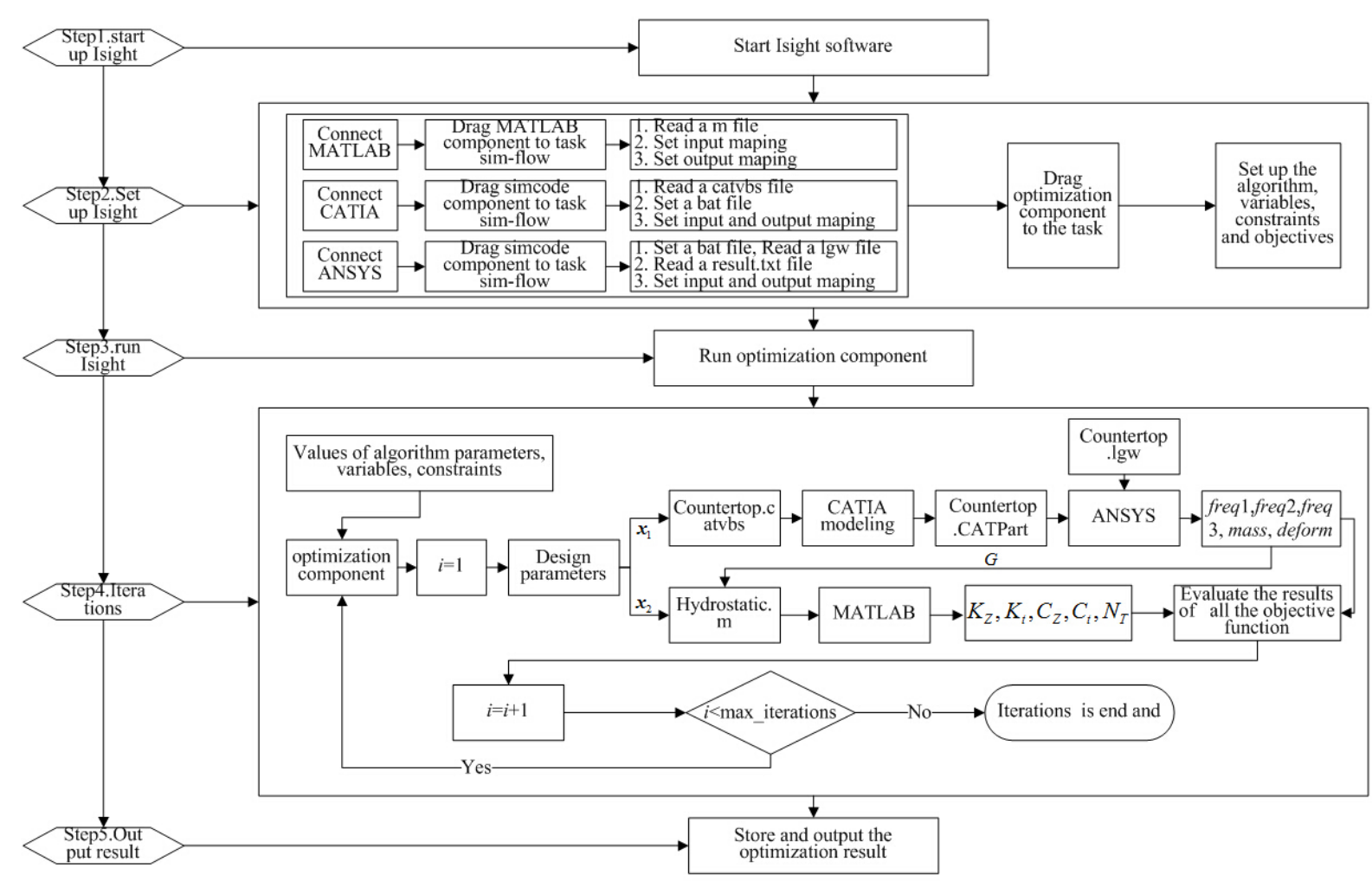

Fig. 5. Optimization implementation framework

In this study, particle swarm optimization (PSO) is selected as the optimization algorithm to optimize the turntable. PSO was proposed by Kennedy and Eberhart [51], Shi, and Eberhart [52] and Kennedy [53]; it is a stochastic optimization method based on swarm intelligence theory. It has been successfully applied in continuous optimization problems such as neural network training [54], voltage stability control [55], distribution route selection [56] and the optimization of cutting parameters [57].

PSO mimics the social behaviour of animal groups such as flocks of birds or fish shoals [58]. The process of finding an optimal design point is similar to the food foraging activity of animals. During the searching process, an animal can obtain maximum global optimization results via group co-operation.
In PSO, particles represent potential solutions of the problem, every particle associated with two parameters: the position $\boldsymbol{x}_{i, d}$ and velocity $\boldsymbol{V}_{i, d}$ in dimension $d$. When PSO is used to search for the best solution of a problem, each particle's movement is influenced by its local best known position, but is also guided toward the best known positions in the searchspace, which are updated as better positions are found by other particles. This is expected to move the swarm toward the best solutions [51]. Specifically, position $\boldsymbol{x}_{i, d}$ and velocity $\boldsymbol{V}_{i, d}$ are updated in $(t+1)^{\text {th }}$ iteration by the equations as follows:

$$
\begin{aligned}
\boldsymbol{V}_{i, d}(t+1)= & w \boldsymbol{V}_{i, d}(t)+ \\
& +\mathrm{c}_{1} r_{1}\left(\text { pbest } \boldsymbol{X}_{i, d}(t)-\boldsymbol{X}_{i, d}(t)\right)+ \\
& +\mathrm{c}_{2} r_{2}\left(\operatorname{gbest} \boldsymbol{X}_{d}(t)-\boldsymbol{X}_{i, d}(t)\right),
\end{aligned}
$$

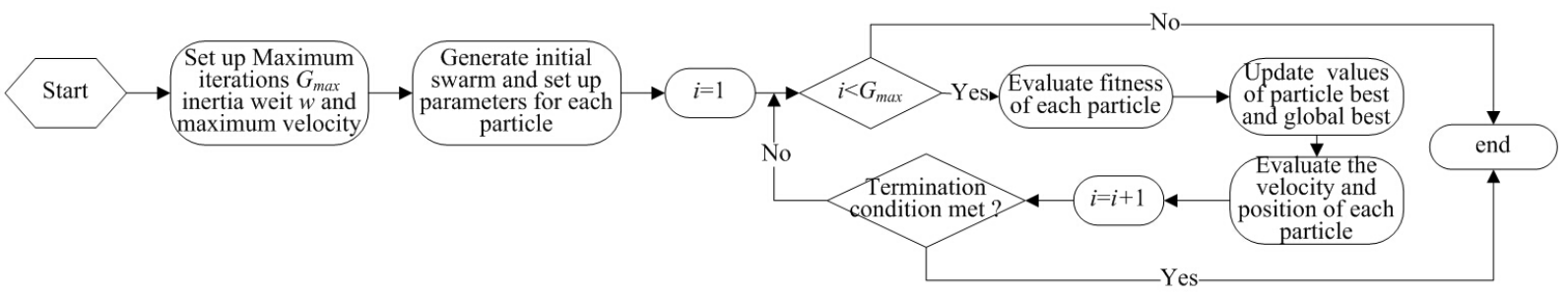

Fig. 6. The implementation procedure of PSO 


$$
\boldsymbol{X}_{i, d}(t+1)=\boldsymbol{X}_{i, d-1}(t)+\boldsymbol{V}_{i, d-1}(t) .
$$

Here $i$ is particle's index and $d$ represents the $d^{\text {th }}$ design parameters, in other words, if there are $n p$ particles and nd design parameters need to be optimized, $V$ and $X$ are matrices of $n p$ rows and nd columns. pbest $\boldsymbol{X}_{i, d}$ is particle $i$ 's personal best experience; gbest $\boldsymbol{X}_{d}$ is the group best experience found by all the particles so far; $c_{1}$ and $c_{2}$ are the acceleration coefficients; $r_{1}$ and $r_{2}$ are two random numbers that generated with the uniform distribution in the range of $[0,1]$; and $w$ is the inertia weight that is used to balance the global/local searches of particles.

The steps of PSO adopted in this research are showed in Fig. 6. First, we need to set up initial values and boundary conditions for all design parameters, maximum iteration times, inertia weight $w$ and the number of particles $n p$. Then the maximum fly velocity $V_{\max }$ should be set up. Thirdly, iterations are processed to obtain the best position of particles by four steps. Step 1: calculate velocity $\boldsymbol{V}_{i, d}$ and position $\boldsymbol{X}_{i, d}$ by Eq. (19) and Eq. (20); Step 2: use new $\boldsymbol{X}_{i, d}$ to calculate new fitness values, where fitness values are $K_{Z}, K_{t}, C_{Z}, C_{t}, N_{t}$ and freq, mass, deform and they are calculated in MATLAB and ANSYS respectively; Step 3: compare fitness values with pbest $\boldsymbol{X}_{i, d}$ and gbest $\boldsymbol{X}_{d}$ then update them according to Eq. (21). Step 4: Finally, determine whether the program meets the termination conditions; if yes, the iterations will stop; if not, return to Step 1 and continue iterating.

$$
\begin{aligned}
& \begin{array}{c}
\text { if }: a d p_{i, d}(t+1)>\text { pbest } \boldsymbol{X}_{i, d}(t) \Rightarrow \\
\quad \operatorname{pbest}_{i, d}(t+1)=a d p_{i, d}(t+1) ;
\end{array} \\
& \text { if : } \operatorname{adp}_{i, d}(t+1) \leq \operatorname{pbest}_{i, d}(t) \Rightarrow \\
& \operatorname{pbest}_{i, d}(t+1)=\operatorname{pbest}_{i, d}(t) ; \\
& \text { if : } \max \left(a d p_{i=1 \sim n p, d}(t+1)\right)>\operatorname{gbest} \boldsymbol{X}_{d}(t) \Rightarrow \\
& \operatorname{gbest}_{d}(t+1)=\max \left(a d p_{i=1 \sim n p, d}(t+1)\right) ; \\
& \text { if : } \max \left(a d p_{i=1 \sim n p, d}(t+1)\right) \leq \operatorname{gbest} \boldsymbol{X}_{d}(t) \Rightarrow \\
& \operatorname{gbest}_{d}(t+1)=\operatorname{gbest} \boldsymbol{X}_{d}(t) .
\end{aligned}
$$

\subsection{Multidisciplinary Design Optimization}

The parameterized FEM of the rotary table countertops is established in CATIA to analyse its sensitivity. The sensitivity of hydrostatic part will be computed according to Eq. (13) and Eq. (16). The normalized results are shown in Fig. 7.

According to Fig. $7 \mathrm{a}$ to $\mathrm{c}$, among all the design parameters of the countertop, $a_{1}, a_{3}, a_{5}, a_{7}$ have major influence on both mass and natural frequency, which means designer should take them seriously and a)
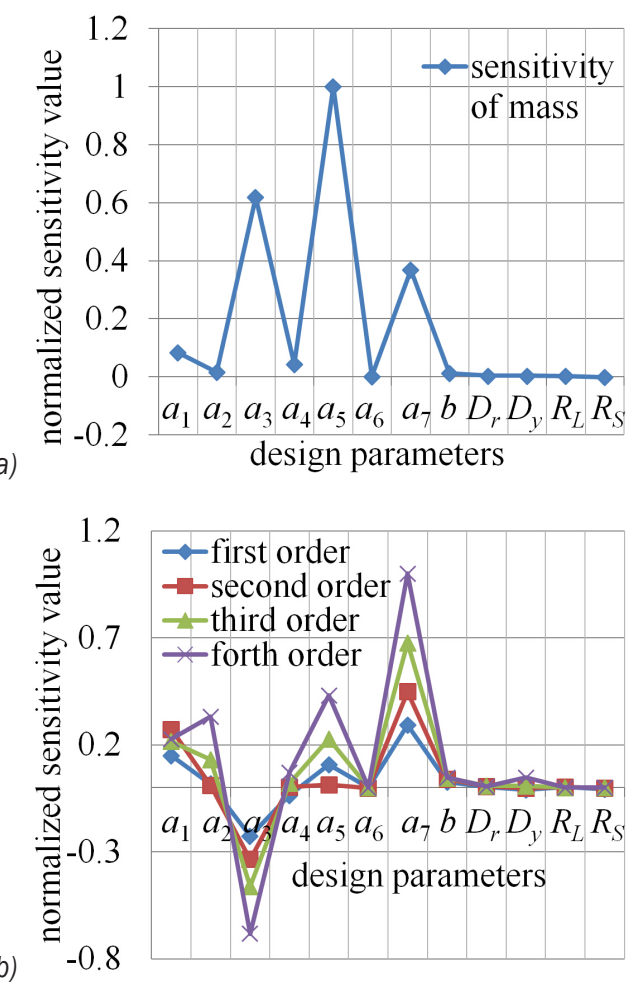
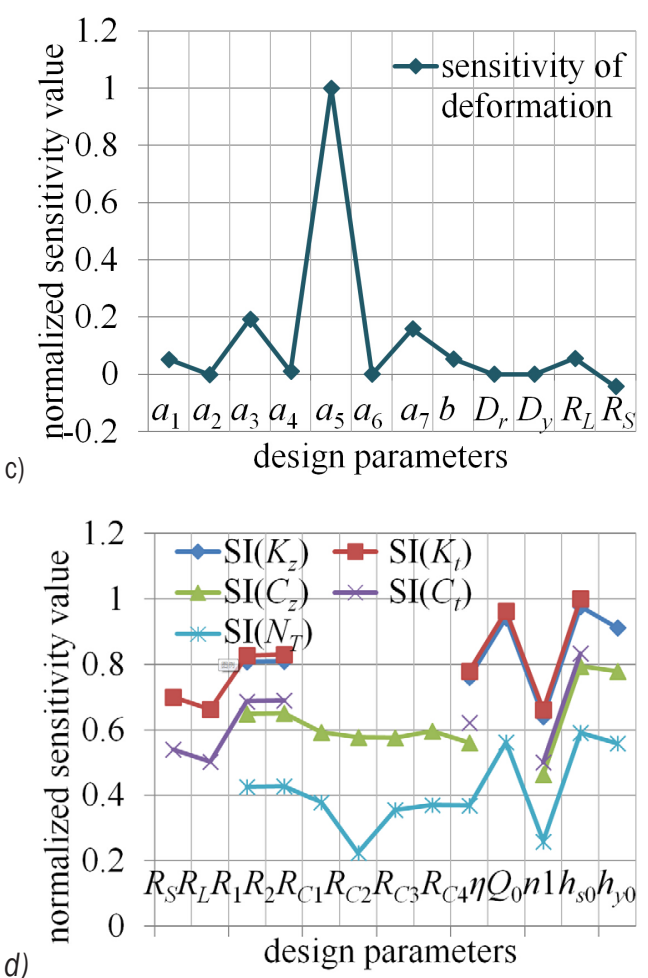

Fig. 7. Analysis results; a) sensitivity of mass, b) sensitivity of natural frequency, c) sensitivity of deformation, and d) sensitivity of $f_{2}$ 
carefully and decide their values. As for the hydrostatic part, film thickness parameters (like: $h_{\mathrm{s} 0}, h_{\mathrm{y} 0}$ ) have the biggest influence on the performance, and in the next place are the flow rate $\left(1 Q_{0}\right)$ and the structural parameters of pads $\left(R_{1}, R_{2}, R_{\mathrm{C} 1}, R_{\mathrm{C} 2}, R_{\mathrm{C} 3}, R_{\mathrm{C} 4}\right)$. The influence of other parameters such as $\eta, n 1, w$ is very small and can be ignored. Therefore, $Q_{0}, R_{1}, R_{2}, R_{\mathrm{C} 1}$, $R_{\mathrm{C} 2}, R_{\mathrm{C} 3}, R_{\mathrm{C} 4}$ can be selected as key parameters to do optimization analysis. The total objective function and constraints can be listed as follows:

Objective:

$$
f=\min \left[f_{1}, f_{2}\right]
$$

subject to:

$$
\begin{array}{ll}
0.64 \mathrm{~m}<a_{1}<0.78 \mathrm{~m} & 0.095 \mathrm{~m}<a_{3}<0.115 \mathrm{~m} \\
0.03 \mathrm{~m}<a_{5}<0.05 \mathrm{~m} & 0.03 \mathrm{~m}<a_{7}<0.05 \mathrm{~m} \\
0.128 \mathrm{~m}<R_{1}<0.192 \mathrm{~m} & 0.14 \mathrm{~m}<R_{2}<0.21 \mathrm{~m} \\
0.140 \mathrm{~m}<R_{\mathrm{C} 1}<0.222 \mathrm{~m} & 0.176 \mathrm{~m}<R_{\mathrm{C} 2}<0.264 \mathrm{~m} \\
0.188 \mathrm{~m}<R_{\mathrm{C} 3}<0.282 \mathrm{~m} & 0.232 \mathrm{~m}<R_{\mathrm{C} 4}<0.348 \mathrm{~m} \\
0.0001 \mathrm{~m}^{3} / \mathrm{s}<Q_{0}<0.0006 \mathrm{~m}^{3} / \mathrm{s} \quad R_{1}<R_{2} \\
0.0002 \mathrm{~m}^{3} / \mathrm{s}<Q_{1}<0.008 \mathrm{~m}^{3} / \mathrm{s} & R_{\mathrm{C} 1}<R_{\mathrm{C} 2}<R_{\mathrm{C} 3}<R_{\mathrm{C} 4} .
\end{array}
$$

In Isight, by connection with MATLAB, CATIA, and ANSYS, the objective functions, constraints and PSO algorithm can be established according to Fig. 5. Better results can be obtained when the particle size is

\begin{tabular}{|c|c|c|c|c|}
\hline Parameters & & Initial value & Result 1 & Result 2 \\
\hline$a_{1}$ & {$[\mathrm{~m}]$} & 0.65 & 0.715 & 0.75 \\
\hline$a_{3}$ & {$[\mathrm{~m}]$} & 0.120 & 0.105 & 0.1 \\
\hline$a_{5}$ & [m] & 0.050 & 0.040 & 0.045 \\
\hline$a_{7}$ & {$[\mathrm{~m}]$} & 0.048 & 0.040 & 0.045 \\
\hline Mass & {$[\mathrm{kg}]$} & $1.1522 \mathrm{e} 5$ & $1.0362 \mathrm{e} 5$ & $1.0907 \mathrm{e} 5$ \\
\hline $\begin{array}{l}\text { first order } \\
\text { natural } \\
\text { frequency }\end{array}$ & {$[\mathrm{Hz}]$} & 31.037 & 33.798 & 36.167 \\
\hline $\begin{array}{l}\text { second } \\
\text { order natural } \\
\text { frequency }\end{array}$ & {$[\mathrm{Hz}]$} & 55.388 & 60.785 & 64.667 \\
\hline $\begin{array}{l}\text { third order } \\
\text { natural } \\
\text { frequency }\end{array}$ & {$[\mathrm{Hz}]$} & 65.023 & 68.527 & 72.846 \\
\hline deformation & {$[\mathrm{m}]$} & $3.50 \mathrm{E}-05$ & 4.16E-05 & 3.67E-05 \\
\hline$R_{1}$ & [m] & 0.15 & 0.16 & 0.17 \\
\hline$R_{2}$ & [m] & 0.165 & 0.175 & 0.19 \\
\hline$R_{C 1}$ & {$[\mathrm{~m}]$} & 0.19 & 0.185 & 0.19 \\
\hline$R_{C 2}$ & [m] & 0.22 & 0.22 & 0.21 \\
\hline$R_{C 3}$ & [m] & 0.24 & 0.235 & 0.23 \\
\hline$R_{C 4}$ & {$[\mathrm{~m}]$} & 0.27 & 0.29 & 0.265 \\
\hline$Q_{0}$ & $10^{-4}\left[\mathrm{~m}^{3} / \mathrm{s}\right]$ & 1.45 & 1.45 & 1.25 \\
\hline$K_{Z}$ & {$[\mathrm{~N} / \mathrm{m}]$} & $2.583 \mathrm{E}+10$ & $2.866 \mathrm{E}+10$ & $3.603 E+10$ \\
\hline$K_{t}$ & {$[\mathrm{~N} \cdot \mathrm{m} / \mathrm{rad}]$} & $1.031 \mathrm{E}+11$ & $1.097 \mathrm{E}+11$ & $1.355 E+11$ \\
\hline$C_{Z}$ & {$[\mathrm{~N} \cdot \mathrm{m} / \mathrm{s}]$} & $7.455 \mathrm{E}+8$ & $9.720 \mathrm{E}+8$ & $1.404 E+9$ \\
\hline$C_{t}$ & {$[\mathrm{~N} \cdot \mathrm{rad} / \mathrm{s}]$} & $2.829 E+9$ & $3.402 \mathrm{E}+9$ & $5.635 E+9$ \\
\hline$N_{\mathrm{T}}$ & {$[\mathrm{W}]$} & $2.649 \mathrm{E}+3$ & $2.554 \mathrm{E}+3$ & $7.963 E+3$ \\
\hline
\end{tabular}
20 , the inertia is $2 \mathrm{e}-3$, the maximum velocity is $1 \mathrm{e}-4$ and the maximum iterations are 800 (these parameters are decided on according to experience). Fig. 8 shows the pareto optimization results, In Fig. 8a, the horizontal axis stands for the dimensionless mass, and the vertical axis are the values of the nondimensional first three order of natural frequency and maximum deformation of the countertop. Similarly, in Fig. 8b, the horizontal axis stands for nondimensional $N_{\mathrm{T}}$, and the vertical axis are nondimensional $K_{Z}, K_{t}, C_{Z}$ and $C_{t}$. The partial optimized results are as shown in Table 1.
Table 1 The partial optimized results

\section{MEASUREMENT VERIFICATION AND ANALYSIS}

According to design experience, Result 1 in Table 1 is selected as the final result, and the correspondingly designed heavy hydrostatic rotary table is shown in Fig. 9. In order to verify the effectiveness and feasibility of the optimization results, experiments
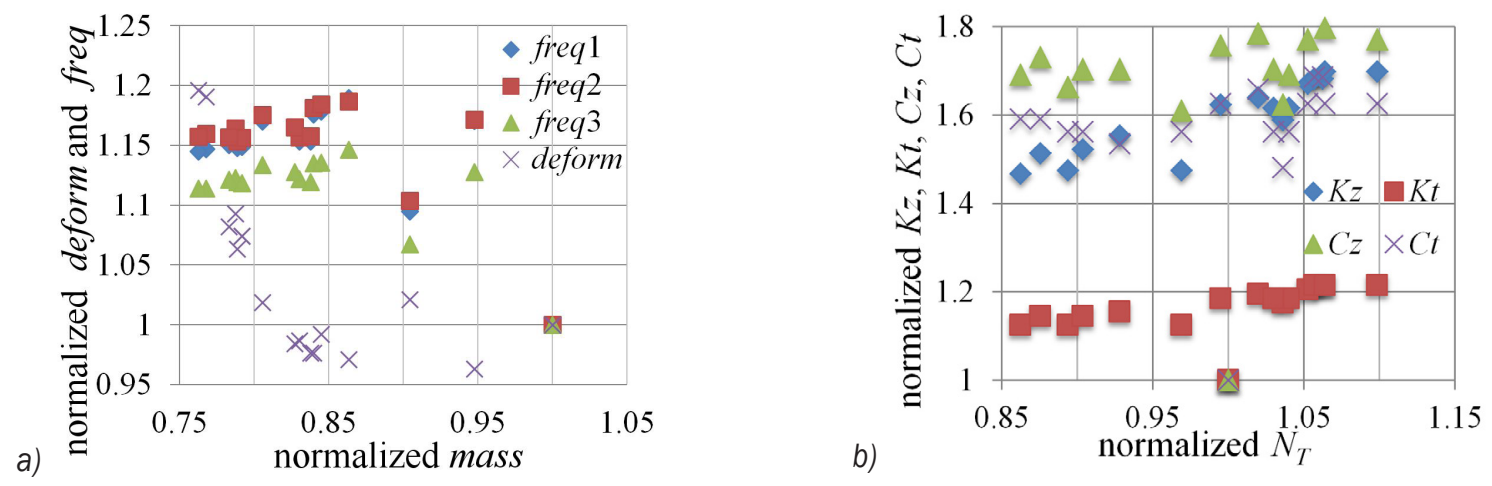

Fig. 8. The pareto optimization results; a) of structure part, and b) of hydrostatic part 
were performed on the turntable bearing after assembly.

The first test was a sweep test, as shown in Fig. 10 , done by exciting countertop of the rotary table about 20 minutes with a vibration exciter, and the sweep range was $5 \mathrm{~Hz}$ to $100 \mathrm{~Hz}$; speed was 0.08 $\mathrm{Hz} / \mathrm{s}$. Finally, we obtained the first, second and third natural frequencies of the countertop. Furthermore, FEM models of the initial and optimized countertops were established in ANSYS to perform a modal analysis. Test and modal analysis results are shown in Table 2. The natural frequency of the countertop after optimization is $33.79 \mathrm{~Hz}$, and the experimental value is $37.25 \mathrm{~Hz}$. The error between them is not large; this means that the simulation results are accurate. Therefore, we can draw that the dynamic performance of the rotary table has been significantly improved.

Table 2. Natural frequencies of rotary table

\begin{tabular}{lccc}
\hline & $\begin{array}{c}\text { First } \\
\text { order }\end{array}$ & $\begin{array}{c}\text { Second } \\
\text { order }\end{array}$ & $\begin{array}{c}\text { Third } \\
\text { order }\end{array}$ \\
\hline $\begin{array}{l}\text { Simulation values for initial design } \\
\text { parameters [Hz] }\end{array}$ & 31.04 & 55.38 & 64.82 \\
\hline $\begin{array}{l}\text { Simulation values for optimized design } \\
\text { parameters [Hz] }\end{array}$ & 33.79 & 60.93 & 68.69 \\
\hline Experimental values [Hz] & 37.25 & 64.09 & 75.58 \\
\hline
\end{tabular}

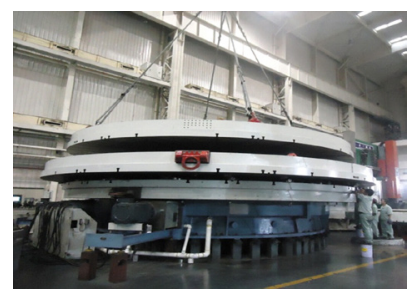

Fig. 9. The optimized hydrostatic rotary table

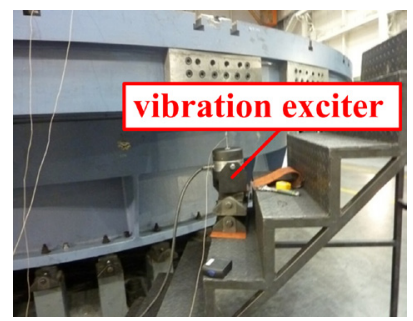

Fig. 10. Sweep test setup

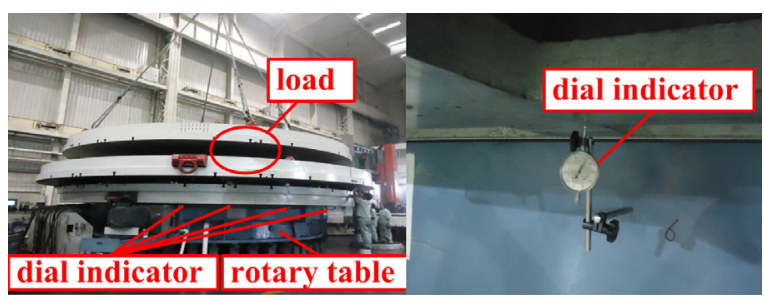

Fig. 11. Bearing capacity experiment setup
Secondly, the bearing capacity of the rotary table was tested, as shown in Fig. 11. The average film thickness of each oil pad was measured by a dial indicator when the rotary table was under different load states. The load varied from $0 \mathrm{t}, 150 \mathrm{t}, 280 \mathrm{t}$ to 410 t. Fig. 12 shows the measurement results when the load is $410 \mathrm{t}$. According to prior experience, the film thickness should be greater than $0.08 \mathrm{~mm}$ when under the maximum load of $410 \mathrm{t}$. Therefore, it can be assumed that the designed rotary table can meet the requirement. The error between experimental and optimized simulation curve is less than $20 \%$, which is within a reasonable range of error. The optimized simulation curve is slightly better than the former film thickness curve, which indicates that the stiffness of the film has gained a certain improvement. Therefore, the above results indicate that this optimization method is effective and feasible.

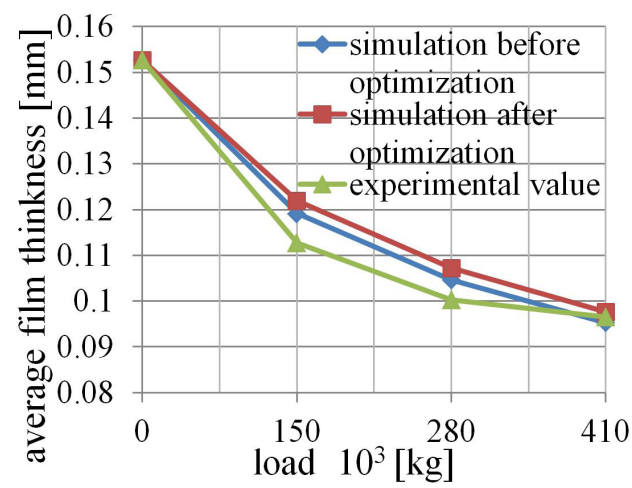

Fig. 12. Film thickness variation of rotary table

\section{CONCLUSION}

A heavy duty hydrostatic rotary table is often used as a means for providing rotational motion and handles supporting and rotating the workpiece in heavy-duty five-axis machine tools. Its rigidity, precision and carrying capacity are directly related to the machining ability and the accuracy of the NC machine tool. Due to the lack of effective means of analysis and experiment, the traditionally designed rotary table cannot provide users with reliable working performance and bearing capacity, and the rail grinding risk will cause serious economic loss to users. Therefore, properly designing a hydrostatic rotary table of a heavy-duty fiveaxis machine tool is very important for machine manufacturers, which aims to reduce its mass, supply pump power and save energy on the premise of good performance. The traditional design of a hydrostatic rotary table is normally performed by different teams sequentially, with expertise in a specific discipline. 
This will cause contradictions and result in excessive iterations, higher costs or longer design process time.

In this paper, a sensitivity-based multidisciplinary optimization design method of a hydrostatic rotary table is proposed. The method takes hydrostatics and the structure's disciplinary characteristics into consideration, and a comprehensive optimization model is established. To achieve the optimization goal, PSO is introduced in Isight with the integration of CATIA, ANSYS, and MATLAB. In order to optimize with good convergence, SA is adopted to identify the key design parameters that have significant influence on the performance of a rotary table.

Characteristics of this method are summarized as follows.

Compared with the current methods in manufacturing, the proposed multidisciplinary optimization method establishes an optimization model with the integration of hydrostatics and structure disciplinary characteristics together, which can reduce the iterative modification caused by sequentially design by experts in different disciplines.

A hydrostatic rotary table is a complex product and has many design parameters, which increases the difficulty of optimization. SA is introduced to identify the key design parameters that significantly influence the performance of hydrostatic rotary tables; therefore, the optimization convergence is improved.

Despite the progress, it is important to note the limitation of the method needed to be further addressed to perfect the current work. In this work, the thermal effect is not considered, and the temperature is still cannot be ignored in the design process. Therefore, the development of an effective approach to integrate the thermodynamics characteristic into the optimization process is another focus for future research.

\section{ACKNOWLEDGEMENT}

The authors are most grateful to Beijing Nova Program (xxjh2015106), Jinghua Talents Programme of Beijing University of Technology, the Leading Talent Project of Guangdong Province, and Open Project of State Key Lab of Digital Manufacturing Equipment \& Technology (Huazhong University of Science and Technology), Shantou Light Industry Equipment Research Institute of science and technology Correspondent Station (2013B090900008) for supporting the research presented in this paper.

\section{REFERENCES}

[1] Suh, S.H., Lee, E.S., Jung, S.Y. (1998). Error modelling and measurement for the rotary table of five-axis machine tools. The International Journal of Advanced Manufacturing Technology, vol. 14, no. 9, p. 656-663, D0l:10.1007/ BF01192286.

[2] Zhang, Y., Yang, J. Zhang, K. (2013). Geometric error measurement and compensation for the rotary table of fiveaxis machine tool with double ballbar. The International Journal of Advanced Manufacturing Technology, vol. 65, no. 1-4, p. 275-281, D0I:10.1007/s00170-012-4166-4.

[3] Mekid, S., Ogedengbe, T. (2010). A review of machine tool accuracy enhancement through error compensation in serial and parallel kinematic machines. International Journal of Precision Technology, vol. 1, no. 3-4, p. 251-286, DOI:10.1504/IJPTECH.2010.031657.

[4] Florussen, G.H.J., Spaan, H.A.M. (2012). Dynamic R-test for rotary tables on 5-axes machine tools. Procedia CIRP, vol. 1, p. 536-539, D0I:10.1016/j.procir.2012.04.095.

[5] Jodei, J., Ebrahimi, M., Roshanian, J. (2009). Multidisciplinary design optimization of a small solid propellant launch vehicle using system sensitivity analysis. Structural and Multidisciplinary Optimization, vol. 38, no. 1, p. 93-100, DOl:10.1007/s00158-008-0260-5.

[6] Schmit, L.A. (1981). Structural synthesis-its genesis and development. AIAA Journal, vol. 19, no. 10, p. 1249-1263, DOI:10.2514/3.7859.

[7] Haftka, R.T. (1977). Optimization of flexible wing structures subject to strength and induced drag constraints. AIAA Journal, vol. 15, no. 8, p. 1101-1106, Dol:10.2514/3.7400.

[8] Lu, S., Kim, H.M. (2010). A regularized inexact penalty decomposition algorithm for multidisciplinary design optimization problems with complementarity constraints. Journal of Mechanical Design, vol. 132, no. 4, p. 1-12, DOI:10.2514/3.7400.

[9] Sobieszczanski-Sobieski, J., Haftka, R.T. (1997). Multidisciplinary aerospace design optimization: survey of recent developments. Structural Optimization, vol. 14, no. 1, p. 1-23, DOI:10.1007/BF01197554.

[10] Agte, J., De Weck, O., Sobieszczanski-Sobieski, J., Arendsen, P., Morris, A., Spieck, M. (2010). MDO: assessment and direction for advancement-an opinion of one international group. Structural and Multidisciplinary Optimization, vol. 40, no. 1-6, p. 17-33, D0I:10.1007/s00158-009-0381-5.

[11] Bi, Z., Wang, L., Wu, C., Yang, G., Zhang, D. (2013). Multidisciplinary Design Optimization in Engineering. Mathematical Problems in Engineering, vol. 2013, article ID 351097, DOI:10.1155/2013/351097.

[12] Yao, W., Chen, X., Ouyang, Q., van Tooren, M. (2012). A surrogate based multistage-multilevel optimization procedure for multidisciplinary design optimization. Structural and Multidisciplinary Optimization, vol. 45, no. 4, p. 559-574, DOI:10.1007/s00158-011-0714-z.

[13] Ning, A., Kroo, I. (2010). Multidisciplinary considerations in the design of wings and wing tip devices. Journal of Aircraft, vol. 47, no. 2, p. 534-543, D0I:10.2514/1.41833. 
[14] Alonso, J.J., Colonno, M.R. (2012). Multidisciplinary optimization with applications to sonic-boom minimization. Annual Review of Fluid Mechanics, vol. 44, p. 505-526, D0l:10.1146/annurev-fluid-120710-101133.

[15] Balling, R., Rawlings, M.R. (2000). Collaborative optimization with disciplinary conceptual design. Structural and Multidisciplinary Optimization, vol. 20, no. 3, p. 232-241, DOl:10.1007/s001580050151.

[16] Geyer, P. (2009). Component-oriented decomposition for multidisciplinary design optimization in building design. Advanced Engineering Informatics, vol. 23, no. 1, p. 12-31, Dol:10.1016/j.aei.2008.06.008.

[17] McAllister, C.D., Simpson, T.W. (2003). Multidisciplinary robust design optimization of an internal combustion engine. Journal of Mechanical Design, vol. 125, no. 1, p. 124-130, DOl:10.1115/1.1543978.

[18] Jixin, W., Mingyao, Y., Yonghai, Y. (2011). Global optimization of lateral performance for two-post ROPS based on the Kriging model and genetic algorithm. Strojniški vestnik - Journal of Mechanical Engineering, vol. 57, no. 10, p. 760-767, DOI:10.5545/sv-jme.2010.246.

[19] Peri, D., Campana, E.F. (2003). Multidisciplinary design optimization of a naval surface combatant. Journal of Ship Research, vol. 47, no. 1, p. 1-12.

[20] Cai, G., Fang, J., Zheng, Y., Tong, X., Chen, J., Wang, J. (2010). Optimization of system parameters for liquid rocket engines with gas-generator cycles. Journal of Propulsion and Power, vol. 26, no. 1, p. 113-119, D0l:10.2514/1.40649.

[21] Yifei, T., Wei, Y., Zhen, Y., Dongbo, L., Xiangdong, L. (2013). Research on multidisciplinary optimization design of bridge crane. Mathematical Problems in Engineering, vol. 2013, article ID 763545, Dol:10.1155/2013/763545.

[22] Kroo, I.M. (1997). MDO for Large-Scale Design. In Alexandrov, N.M., Hussaini, M.Y. (eds.) Multidisciplinary Design Optimization: State-of-the-Art, SIAM, Philadelphia, p. 22-44.

[23] Sobieszczanski-Sobieski, J., Haftka, R.T. (1997). Multidisciplinary aerospace design optimization: survey of recent developments. Structural Optimization, vol. 14, no. 1, p. 1-23, DOl:10.1007/BF01197554.

[24] Martins, J.R., Lambe, A.B. (2013). Multidisciplinary design optimization: a survey of architectures. AIAA Journal, vol. 51, no. 9, p. 2049-2075, D0l:10.2514/1.J051895.

[25] Zhang, X., Huang, H.Z. (2010). Sequential optimization and reliability assessment for multidisciplinary design optimization under aleatory and epistemic uncertainties. Structural and Multidisciplinary Optimization, vol. 40, no. 1-6, p. 165-175, DOI:10.1007/s00158-008-0348-y.

[26] Du, X., Guo, J., Beeram, H. (2008). Sequential optimization and reliability assessment for multidisciplinary systems design. Structural and Multidisciplinary Optimization, vol. 35, no. 2, p. 117-130, D0l:10.1007/s00158-007-0121-7.

[27] Yao, W., Chen, X., Luo, W., van Tooren, M., Guo, J. (2011). Review of uncertainty-based multidisciplinary design optimization methods for aerospace vehicles. Progress in Aerospace Sciences, vol. 47, no. 6, p. 450-479, D0l:10.1016/j. paerosci.2011.05.001.

[28] Zeeshan Q, Yunfeng D, Rafique AF, et al. (2010). Multidisciplinary robust design and optimization of multistage boost phase interceptor. 51st AIAA/ASME/ASCE/AHS/ASC Structures, Structural Dynamics, and Materials Conference, Orlando, DOI:10.2514/6.2010-2920.

[29] Rowe, W.B. (2013). Hydrostatic and Hybrid Bearing Design. Elsevier, London.

[30] Bassani, R., Piccigallo, B. (1992). Hydrostatic Lubrication. Tribology Series, vol. 22, Elsevier, Amsterdam.

[31] Hamrock, B.J., Schmid, S.R., Jacobson, B.O. (2004). Fundamentals of Fluid Film Lubrication. CRC Press, Boca Raton, DOI:1201/9780203021187.

[32] Ting, L.L., Mayer, J.E. (1971). The effects of temperature and inertia on hydrostatic thrust bearing performance. Journal of Tribology, vol. 93, no. 2, p. 307-312, D0I:10.1115/1.3451572.

[33] Deb, K., Goyal, M. (1997). Optimizing Engineering Designs Using a Combined Genetic Search. Proceedings of the $6^{\text {th }}$ International Conference on Genetic Algorithms, p. 521-528.

[34] Lin, J.R. (2000). Surface roughness effect on the dynamic stiffness and damping characteristics of compensated hydrostatic thrust bearings. International Journal of Machine Tools and Manufacture, vol. 40, no. 11, p. 1671-1689, D0l:10.1016/S0890-6955(00)00012-2.

[35] Bakker, O.J., Van Ostayen, R.A.J. (2010). Recess depth optimization for rotating, annular, and circular recess hydrostatic thrust bearings. Journal of Tribology, vol. 132, no. 1, p. 11-13, Dol:10.1115/1.4000545.

[36] Zhao Ming, Huang Zhengdong, Li Bing, Chen Liping. (2007). Hydrostatic pressure calculation and optimization for design of beam and slide-rest guideways in heavy duty CNC vertical turning mill. Chinese Journal of Mechanical Engineering (English Edition), vol. 20, no. 5, p. 16-22, Dol:10.3901/ CJME.2007.05.016.

[37] Solmaz, E., Öztürk, F. (2006). Optimisation of hydrostatic journal bearings with parameter variations based on thermodynamic effects. Industrial Lubrication and Tribology, vol. 58, no. 2, p. 118-122, Dol:10.1108/00368790610651530.

[38] Karkee, M., Steward, B.L. (2010). Local and global sensitivity analysis of a tractor and single axle grain cart dynamic system model. Biosystems Engineering, vol. 106, no. 4, p. 352-366, D0I:10.1016/j.biosystemseng.2010.04.006.

[39] Bo, L., Kyu, P.N. (2013). Sensitivity analysis for identifying the critical productivity factors of container terminals. Strojniški vestnik - Journal of Mechanical Engineering, vol. 59, no. 9, p. 536-546, DOl:10.5545/sv-jme.2012.931.

[40] Xu, C., Gertner, G. (2007). Extending a global sensitivity analysis technique to models with correlated parameters. Computational Statistics \& Data Analysis, vol. 51, no. 12, p. 5579-5590, DOI:10.1016/j.csda.2007.04.003.

[41] Rodriguez-Fernandez, M., Banga, J.R. (2009). Global sensitivity analysis of a biochemical pathway model. $2^{\text {nd }}$ International Workshop on Practical Applications of Computational Biology and Bioinformatics, Advances in Soft Computing, vol. 49, p. 233-242, Springer, Berlin, Heidelberg, D0I:10.1007/978-3540-85861-4_28.

[42] Saltelli, A., Ratto, M., Tarantola, S., Campolongo, F., Commission, E. (2006). Sensitivity analysis practices: Strategies for model-based inference. Reliability Engineering \& System Safety, vol. 91, no. 10-11, p. 1109-1125, D0I:10.1016/j.ress.2005.11.014. 
[43] Helton, J.C., Davis, F.J. (2003). Latin hypercube sampling and the propagation of uncertainty in analyses of complex systems. Reliability Engineering \& System Safety, vol. 81, no. 1, p. 23-69, DOl:10.1016/S0951-8320(03)00058-9.

[44] Saltelli, A., Chan, K., Scott, E.M. (eds.) (2000). Sensitivity Analysis, vol. 1, Wiley, New York.

[45] Sudret, B. (2008). Global sensitivity analysis using polynomial chaos expansions. Reliability Engineering \& System Safety, vol. 93, no. 7, p. 964-979, D0l:10.1016/j.ress.2007.04.002.

[46] Maly, T., Petzold, L.R. (1996). Numerical methods and software for sensitivity analysis of differential-algebraic systems. Applied Numerical Mathematics, vol. 20, no. 1-2, p. 57-79, Dol:10.1016/0168-9274(95)00117-4.

[47] Leis, J.R., Kramer, M.A. (1988). Algorithm 658: ODESSA-an ordinary differential equation solver with explicit simultaneous sensitivity analysis. ACM Transactions on Mathematical Software, vol. 14, no. 1, p. 61-67, Dol:10.1145/42288.214371.

[48] Saltelli, A., Tarantola, S., Chan, K.P.-S. (1999). A quantitative model-independent method for global sensitivity analysis of model output. Technometrics, vol. 41, no. 1, p. 39-56, DOl:10.1080/00401706.1999.10485594.

[49] Morris, M.D. (1991). Factorial sampling plans for preliminary computational experiments. Technometrics, vol. 33, no. 2, p. 161-174, DOI:10.1080/00401706.1991.10484804.

[50] Koch, P.N., Evans, J.P., Powell, D. (2002). Interdigitation for effective design space exploration using iSIGHT. Structural and Multidisciplinary Optimization, vol. 23, no. 2, p. 111-126, DOI:10.1007/s00158-002-0171-9.

[51] Kennedy, J., Eberhart, R. (1995). Particle Swarm Optimization. Proceedings of IEEE International Conference on Neural Networks, Vol. 4, p. 1942-1948, D0l:10.1109/ ICNN.1995.488968.

[52] Shi, Y., Eberhart, R.C. (1998). A modified particle swarm optimizer. Proceedings of IEEE International Conference on Evolutionary Computation, p. 69-73, D0l:10.1109/ icec.1998.699146.

[53] Kennedy, J. (1997). The particle swarm: social adaptation of knowledge. Proceedings of IEEE International Conference on Evolutionary Computation, p. 303-308, D0l:10.1109/ ICEC.1997.592326.

[54] Van den Bergh, F., Engelbrecht, A.P. (2000). Cooperative learning in neural networks using particle swarm optimizers. South African Computer Journal, vol. 26, p. 8490.

[55] Fukuyama, Y., Nakanishi, Y. (1999). A particle swarm optimization for reactive power and voltage control considering voltage stability. Proceedings of IEEE international conference on intelligent system applications to power systems, Rio de Janeiro.

[56] Wu, Z. (2014). Optimization of distribution route selection based on particle swarm algorithm. International Journal of Simulation Modelling, vol. 13, no. 2, p. 230-242, D0l:10.2507/ IJSIMM13(2)C09.

[57] Župerl, U., Čuš, F., Gečevska, V. (2007). Optimization of the characteristic parameters in milling using the pso evaluation technique. Strojniški vestnik - Journal of Mechanical Engineering, vol. 53, no. 6, p. 354-368.

[58] Yeh, W.C., Lin, Y.C., Chung, Y.Y., Chih, M. (2010). A particle swarm optimization approach based on Monte Carlo simulation for solving the complex network reliability problem. IEEE Transactions on Reliability, vol. 59, no. 1, p. 212-221, DOI:10.1109/TR.2009.2035796.

\section{NOMENCLATURE}

$C_{S i} \quad[\mathrm{~N} \cdot \mathrm{s} / \mathrm{m}]$ damping coefficients of ith supporting pads

$C_{t} \quad[\mathrm{~N} \cdot \mathrm{rad} / \mathrm{s}]$ incline damping coefficients of the turntable

$\begin{array}{lll}C_{y} & {[\mathrm{~N} \cdot \mathrm{s} / \mathrm{m}]} & \text { damping coefficients of preloaded }\end{array}$ pads

$C_{z} \quad[\mathrm{~N} \cdot \mathrm{s} / \mathrm{m}]$ axial damping coefficients of the turntable

$\begin{array}{lll}f & {[-]} & \text { objective function of all the part }\end{array}$

$f_{1} \quad[-] \quad$ objective function for countertop

$\boldsymbol{f}_{2} \quad[-] \quad$ objective function for hydrostatic

$F_{i} \quad[\mathrm{~N}]$

$F_{y} \quad[\mathrm{~N}]$

$G \quad[\mathrm{~N}]$

$h_{i} \quad[\mathrm{~mm}]$

$h_{y} \quad[\mathrm{~mm}]$ part load-carrying capacity of ith supporting pads

load-carrying capacity of preloaded pads

weight of the countertop

$K_{S i} \quad[\mathrm{~N} / \mathrm{m}]$

film thickness of ith supporting pads

$K_{t} \quad[\mathrm{~N} \cdot \mathrm{m} / \mathrm{rad}]$ incline stiffness of the turntable

$\begin{array}{ll}K_{y} & {[\mathrm{~N} / \mathrm{m}] \quad \text { stiffness of preloaded pads }}\end{array}$

$K_{z} \quad[\mathrm{~N} / \mathrm{m}]$

$N_{T} \quad[\mathrm{~W}]$

$N_{T i} \quad[\mathrm{~W}]$

$N_{T y} \quad[\mathrm{~W}]$

$p_{0 i} \quad[\mathrm{~Pa}]$

$p_{0 y} \quad[\mathrm{~Pa}]$

$p_{i}(r) \quad[\mathrm{Pa}]$

$p_{1 y}(r) \quad[\mathrm{Pa}]$

$p_{2 y}(r) \quad[\mathrm{Pa}]$

$Q_{0} \quad\left[\mathrm{~m}^{3} / \mathrm{s}\right]$

$Q_{1} \quad\left[\mathrm{~m}^{3} / \mathrm{s}\right]$ axial stiffness of the turntable overall pump power pump power of $i$ 'th supporting pads pump power of preloaded pads recess pressure of i'th supporting pads recess pressure of preloaded pads film pressure of i'th supporting pads

film pressure of inner land in preloaded pads

ilm pressure of outer land in preloaded pads

flow rate which supply to every supporting pads

flow rate which supply to preloaded pads 


\section{APPENDIX}

In this study, it is assumed that thin film lubrication theory is applicable and the flow in bearing is isothermal, laminar and axisymmetric. So the $N-S$ equations can be simplified as:

$$
\begin{gathered}
\frac{1}{r} \frac{\partial\left(r u_{r}\right)}{\partial r}+\frac{\partial\left(v_{z}\right)}{\partial z}=0 \\
\frac{\partial p}{\partial r}=\eta \frac{\partial^{2} u_{r}}{\partial z^{2}} \\
\frac{\partial p}{\partial z}=0
\end{gathered}
$$

Film pressure has no change in $z$ direction according to Eq. (A3) above, so integrating both sides of Eq. (A2) with boundary conditions: $z=h, u_{r}=0 ; z=0, u_{r}=0$; at the surface of the pad, then the radial velocity is found to be:

$$
u_{r}=\frac{z(z-h)}{2 \eta} \frac{\partial p}{\partial r}
$$

Substituting Eq. (A4) into Eq. (A1) and integrating it with boundary conditions: $z=h, u_{r}=0 ; v_{z}=\partial h / \partial t ; z=0$, $u_{r}=0, v_{z}=0$, then the Reynolds equation is obtained as:

$$
\frac{1}{r} \frac{\partial}{\partial r}\left(\frac{r h^{3}}{12 \eta} \frac{\partial p}{\partial r}\right)=\frac{\partial h}{\partial t} .
$$

Integrating Eq. (A4) at $z \in(0, h)$ and $\varphi \in(0,2 \pi)$ the flow rate is:

$$
Q(r)=\int_{0}^{2 \pi} \int_{0}^{h} u_{r} r d z d \varphi=-\frac{\pi r h^{3}}{6 \eta} \frac{\partial p}{\partial r},
$$

where $r$ is radius, $h$ is film thickness, $p$ is film pressure, $t$ is time, and $\eta$ is lubricant viscosity.

For supporting pad (shown in Fig. 3) $h \Rightarrow h_{i}(i=1,2,3, \sim n) ; \quad p \Rightarrow p_{i}$. we have

Integrating both sides of Eq. (A5) two times for $r$, then

$$
p_{i}(r)=\frac{12 \eta}{h_{i}^{3}}\left(\mathrm{~A} \ln (r)+\mathrm{B}+\frac{r^{2}}{4} \frac{\partial h_{i}}{\partial t}\right)
$$

where $\mathrm{A}$ and $\mathrm{B}$ are unknown constants. The boundary conditions for circular recess pads can be provided in Eq. (A8):

$$
\left\{\begin{array}{l}
\text { when } r=R_{1}, p_{i}=p_{0 i} \\
\text { when } r=R_{2}, p_{i}=0
\end{array} .\right.
$$

Substituting the boundary conditions into Eq. (A7), we can gotten that:

$$
\left\{\begin{array}{l}
A=\frac{1}{\ln \left(\frac{R_{1}}{R_{2}}\right)}\left(\frac{h_{i}^{3}}{12 \eta} p_{0 i}-\frac{R_{1}^{2}-R_{2}^{2}}{4} \frac{\partial h_{i}}{\partial t}\right) \\
B=\frac{-1}{\ln \left(\frac{R_{1}}{R_{2}}\right)}\left(\frac{h_{i}^{3} \ln \left(R_{2}\right)}{12 \eta} p_{0 i}-\frac{R_{1}^{2} \ln \left(R_{2}\right)-R_{2}^{2} \ln \left(R_{1}\right)}{4} \frac{\partial h_{i}}{\partial t}\right)
\end{array} .\right.
$$

Substituting Eq. (A9) into Eq. (A7), then the pressure distribution can obtained:

$$
\begin{aligned}
& p_{i}(r)=p_{0 i} \frac{\ln \left(\frac{r}{R_{2}}\right)}{\ln \left(\frac{R_{1}}{R_{2}}\right)}+ \\
& +\left(\frac{3 \eta r^{2}}{h_{i}^{3}}+\frac{3 \eta\left(R_{2}^{2} \ln \left(\frac{r}{R_{1}}\right)-R_{1}^{2} \ln \left(\frac{r}{R_{2}}\right)\right)}{h_{i}^{3} \ln \left(\frac{R_{1}}{R_{2}}\right)}\right) \frac{\partial h_{i}}{\partial t} .
\end{aligned}
$$

Assuming fluid incompressible, the lubricant flowing out from $i^{\text {th }}$ pad is can be divided in two parts; one is $Q_{0}$ flow from the pump, another is caused by squeeze velocity and the flow rate of this part is: $-\pi R_{2}^{2} \frac{\partial h_{i}}{\partial t}$. So the flow continuity equation is $Q\left(R_{2}\right)=Q_{0}-\pi R_{2}^{2} \frac{\partial h_{i}}{\partial t}$. Substituting Eq. (A9) and Eq. (A10) into the flow continuity equation, then recess pressure can be calculated:

$$
p_{0 i}=\frac{6 \eta Q_{0}}{\pi h_{i}^{3}} \ln \left(\frac{R_{2}}{R_{1}}\right)-\frac{3 \eta\left(R_{2}^{2}-R_{1}^{2}\right)}{h_{i}^{3}} \frac{\partial h_{i}}{\partial t} .
$$

Then, the load-carrying capacity of the bearing can be calculated by integrating the mean steady hydrostatic film pressure:

$$
\begin{aligned}
& F_{i}=\pi R_{1}^{2} p_{0 i}+2 \pi \int_{R_{1}}^{R_{2}} r p_{i}(r) d r= \\
& =\frac{3 \eta\left[2 Q_{0}-\pi\left(R_{2}^{2}+R_{1}^{2}\right) \frac{\partial h_{i}}{\partial t}\right]\left(R_{2}^{2}-R_{1}^{2}\right)}{2 h_{i}^{3}} .
\end{aligned}
$$

In addition, the stiffness, the damping coefficients and the pump power are obtained as follows:

$$
\left\{\begin{array}{l}
K_{S i}=-\left.\frac{\partial F_{i}}{\partial h_{i}}\right|_{\frac{\partial h_{i}}{\partial t}=0}=\frac{9 Q_{0} \eta\left(R_{2}^{2}-R_{1}^{2}\right)}{h_{i}^{4}} \\
C_{S i}=-\frac{\partial F_{i}}{\partial\left(\frac{\partial h_{i}}{\partial t}\right)}=\frac{3 \pi \eta\left(R_{2}^{4}-R_{1}^{4}\right)}{2 h_{i}^{3}} \\
N_{T i}=p_{0 i}\left(\frac{\partial h_{i}}{\partial t}=0\right) Q_{0}=\frac{6 \eta \ln \left(\frac{R_{2}}{R_{1}}\right) Q_{0}^{2}}{\pi h_{i}^{3}}
\end{array} .\right.
$$

For annular recess pad (shown in Fig. 4), its boundary conditions are: 


$$
\left\{\begin{array}{l}
p=p_{y} ; h=h_{y} \\
\text { when } r=R_{C 1}, p_{y}=0 ; \text { when } r=R_{C 2}, p_{y}=p_{0 y} \\
\text { when } r=R_{C 3}, p_{y}=p_{0 y} ; \text { when } r=R_{C 4}, p_{y}=0 . \\
Q_{1}-\pi\left(R_{C 4}^{2}-R_{C 1}^{2}\right) \frac{\partial h_{y}}{\partial t}=-Q\left(R_{C 1}\right)+Q\left(R_{C 4}\right)
\end{array} .\right.
$$

When $r \in\left(R_{C 3}, R_{C 4}\right)$, the pressure distribution is same as Eq. (A10). By replacing $R_{1}, R_{2}, p_{0 i}$ and $h_{i}$ with $R_{C 3}, R_{C 4}$, $p_{0 y}$ and $h_{y}, p_{2 y}(r)$ can be written as:

$$
\begin{aligned}
& p_{2 y}(r)=p_{0 y} \frac{\ln \left(\frac{r}{R_{C 4}}\right)}{\ln \left(\frac{R_{C 3}}{R_{C 4}}\right)}+ \\
& +\left(\frac{3 \eta r^{2}}{h_{y}^{3}}+\frac{3 \eta\left(R_{C 4}^{2} \ln \left(\frac{r}{R_{C 3}}\right)-R_{C 3}^{2} \ln \left(\frac{r}{R_{C 4}}\right)\right)}{h_{y}^{3} \ln \left(\frac{R_{C 3}}{R_{C 4}}\right)}\right) \frac{\partial h_{y}}{\partial t} .
\end{aligned}
$$

When $r \in\left(R_{C 1}, R_{C 2}\right)$, substituting the boundary conditions $p_{y}\left(R_{C 1}\right)=0, p_{y}\left(R_{C 2}\right)=p_{0 y}$ into Eq. (A7), we can get that:

$$
\left\{\begin{aligned}
A & =\frac{1}{\ln \left(R_{C 2}\right)-\ln \left(R_{C 1}\right)}\left(\frac{h_{y}^{3}}{12 \eta} p_{0 y}-\frac{R_{C 2}^{2}-R_{C 1}^{2}}{4} \frac{\partial h_{y}}{\partial t}\right) \\
B & =\frac{1}{\ln \left(R_{C 1}\right)-\ln \left(R_{C 2}\right)}\left(\frac{h_{y}^{3} \ln \left(R_{C 1}\right)}{12 \eta} p_{0 y}-\right. \\
& \left.-\frac{R_{C 2}^{2} \ln \left(R_{C 1}\right)-R_{C 1}^{2} \ln \left(R_{C 2}\right)}{4} \frac{\partial h_{y}}{\partial t}\right)
\end{aligned}\right.
$$

Substituting Eq. (A16) into Eq. (A7), we have:

$$
\begin{aligned}
p_{1 y}(r) & =p_{0 y} \frac{\ln \left(\frac{r}{R_{C 1}}\right)}{\ln \left(\frac{R_{C 2}}{R_{C 1}}\right)}+ \\
& +\left(\frac{3 \eta r^{2}}{h_{y}^{3}}+\frac{3 \eta\left(R_{C 1}^{2} \ln \left(\frac{r}{R_{C 2}}\right)-R_{C 2}^{2} \ln \left(\frac{r}{R_{C 1}}\right)\right)}{h_{y}^{3} \ln \left(\frac{R_{C 2}}{R_{C 1}}\right)}\right) \frac{\partial h_{y}}{\partial t} .
\end{aligned}
$$

Substituting Eq. (A6), (A15) and (A17) into flow continuity equation:

$$
Q_{1}-\pi\left(R_{C 4}^{2}-R_{C 1}^{2}\right) \frac{\partial h_{y}}{\partial t}=-Q\left(R_{C 1}\right)+Q\left(R_{C 4}\right)
$$

then recess pressure can be calculated:

$$
p_{0 y}=\frac{3 \eta\left[\begin{array}{l}
2 Q_{1} \ln \left(\frac{R_{C 1}}{R_{C 2}}\right) \ln \left(\frac{R_{C 4}}{R_{C 3}}\right)+ \\
\left.+\pi\left(\ln \left(\frac{R_{C 1}}{R_{C 2}}\right)\left(R_{C 3}^{2}-R_{C 4}^{2}\right)+\ln \left(\frac{R_{C 4}}{R_{C 3}}\right)\left(R_{C 1}^{2}-R_{C 2}^{2}\right)\right) \frac{\partial h_{y}}{\partial t}\right]
\end{array}\right.}{\pi h_{y}^{3} \ln \left(\frac{R_{C 1} R_{C 3}}{R_{C 2} R_{C 4}}\right)} .
$$

The load-carrying capacity of the bearing can be calculated by integrating the hydrostatic film pressure.

$$
\begin{aligned}
& F_{y}=\pi\left(R_{C 3}^{2}-R_{C 2}^{2}\right) p_{0 y}+2 \pi \int_{R_{c 1}}^{R_{c 2}} r p_{1 y}(r) d r+2 \pi \int_{R_{c 3}}^{R_{c 3}} r p_{2 y}(r) d r=
\end{aligned}
$$

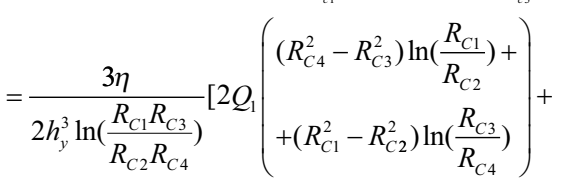

$$
\begin{aligned}
& \left.+\pi\left(\begin{array}{l}
\left(R_{C 1}^{4}-R_{C 2}^{4}+R_{C 3}^{4}-R_{C 4}^{4}\right) \ln \left(\frac{R_{C 1} R_{C 3}}{R_{C 2} R_{C 4}}\right)- \\
-\left(R_{C 1}^{2}-R_{C 2}^{2}+R_{C 3}^{2}-R_{C 4}^{2}\right)^{2}
\end{array}\right) \frac{\partial h_{y}}{\partial t}\right] .
\end{aligned}
$$

Then the stiffness, the damping coefficients and the pump power are obtained as follows:

$$
\begin{gathered}
K_{y}=\frac{9 Q_{1} \eta\left(\left(R_{C 4}^{2}-R_{C 3}^{2}\right) \ln \left(\frac{R_{C 1}}{R_{C 2}}\right)+\left(R_{C 1}^{2}-R_{C 2}^{2}\right) \ln \left(\frac{R_{C 3}}{R_{C 4}}\right)\right)}{h_{y}^{4} \ln \left(\frac{R_{C 1} R_{C 3}}{R_{C 2} R_{C 4}}\right)},\left(\begin{array}{l}
\left.\left(R_{C 1}^{4}-R_{C 2}^{4}+R_{C 3}^{4}-R_{C 4}^{4}\right) \ln \left(\frac{R_{C 1} R_{C 3}}{R_{C 2} R_{C 4}}\right)-\right) \\
-\left(R_{C 1}^{2}-R_{C 2}^{2}+R_{C 3}^{2}-R_{C 4}^{2}\right)^{2}
\end{array}\right. \\
C_{y}=\frac{2 h_{y}^{3} \ln \left(\frac{R_{C 1} R_{C 3}}{R_{C 2} R_{C 4}}\right)}{6 \eta \ln \left(\frac{R_{C 4}}{R_{C 3}}\right) \ln \left(\frac{R_{C 2}}{R_{C 1}}\right) Q_{1}^{2}} \\
N_{T y}=p_{0 y} Q_{1}=\frac{\pi h_{y}^{3} \ln \left(\frac{R_{C 4} R_{C 2}}{R_{C 3} R_{C 1}}\right)}{}
\end{gathered}
$$

